\title{
Special Issue: Supply Chain and Logistics Decisions under Environmental Aspect
}

\author{
Nelishan Demirel (D) \\ Erciyes University, Department of International Trade and Logistics, Kayseri (Turkey) \\ ndemirel@,ercijes.edu.tr
}

Received: March 2017

Accepted: April 2017

\section{Abstract:}

This editor's note has a twofold objective: (1) to present a brief summary about the environmental issues in supply chain and logistics decisions (2) to present general information about the papers published in the special issue.

\section{Introduction}

This special issue of the Journal of Industrial Engineering and Management is focused on incorporating environmental issues into supply chain and logistics decisions because of damaging effects of increasing waste quantities all over the world. Management of returned products becomes vitally important not only because of environmental effects of increasing waste quantities but also economical factors and social concerns. There are also enacted obligations by governments encumbering manufacturers to minimize the produced waste, limit the used hazardous materials and incorporate environmental factors into their decisions in several industries. Reverse logistics activities are more important in certain industries such as packaging, electrical and electronic equipment, battery and automobile (Demirel, Demirel \& Gökçen, 2016). 
The reverse processes tend to save energy, consume less material and often have a lower impact on the environment than the manufacturing counterparts that make brand new products from virgin materials (Chen \& Chang, 2012). Collection, inspection and sorting, re-processing, disposal and re-distribution are the main reverse logistics processes. Collection, re-processing and re-distribution processes are common for all firms that incorporate reverse flows to their systems. The main difference between the options becomes in re-processing. Used products can be re-processed in a variety of ways. These product recovery options can be classified as repairing, refurbishing, remanufacturing, cannibalization, and recycling (Thierry Salomon, Van Nunen \& Van Waasenhove, 1995). Reusing is also possible directly or after little processing (e.g. cleaning) for some products such as containers. There is no doubt that the most preferred behavior should be waste prevention. When none of mentioned options is applicable because of technical and economical obstacles, as a last resort, proper disposal should be carried out. In one way or another, in order to continue to thrive on this planet, our lifestyles will need to become more sustainable, proper management of returned products will need to be more considered and environmentally friendly decisions will need to be taken from obtaining the raw materials to delivery of products to customers. This Special Issue gathers the 10 manuscripts that significantly contribute to the managing of end-of-life products and wastes properly in order to comply with governmental regulations, environmental and social requirements and/or gain economical benefit.

\section{Overview of the papers}

The papers chosen for this Special Issue were selected for their quality, their originality and their connection with the Special Issue's motto Supply Chain and Logistics Decisions under Environmental Aspect. The papers selected for this Special Issue are organized as follows:

- A.Y. Alqahtani and S.M. Gupta "Optimizing Two-Dimensional Renewable Warranty for Sensor Embedded Remanufactured Products" proposed a discrete-event simulation model to optimize the implementation of a two-dimensional renewing warranty policy for remanufactured products. In order to determine the optimum strategy offered by the remanufacturer, various warranty and preventive maintenance scenarios were analyzed in the manuscript.

- M. Hashim et al. presented a fuzzy multi-objective model for the sustainable strategic supplier selection (SSSS) issue in fuzzy environment in their manuscript "Application of Multi-objective Optimization based on Genetic Algorithm for Sustainable Strategic Supplier Selection under Fuzzy Environment". They considered three objectives: minimizing lean cost, maximizing sustainable service and greener product quality level in their model. They proposed a genetic algorithm approach for solving the SSSS problem. 
- In his manuscript "Green Supply Chain Management using the Queuing Theory to Handle Congestion and Reduce Energy Consumption and Emissions from Supply Chain Transportation Fleet" A. Aziziankohan, F. Jolai, M. Khalilzadeh, R. Soltani and R. Tavakkoli-Moghaddam examined the effect of reducing energy consumption in green supply chain by using queuing theory and transportation models. The proposed model is solved for a supply chain including one warehouse, two plants, two distributors and one recycling center.

- In "Optimal Inventory Policy in a Closed Loop Supply Chain System with Multiple Periods", authors proposed a mixed integer linear programming model considering the fixed order quantity inventory policy in various sites at multiple periods in order to maximize the profit of the closed loop supply chain.

- In "Electric vehicle battery reuse: preparing for a second life" authors analyzed the second life opportunities for end-of-life batteries and determined a possible location for a battery remanufacturing facility considering productivity and environment.

- In the manuscript entitled "The application of the triple bottom line approach to sustainability assessment: the case study of the UK automotive supply chain", authors aimed to assess the level of sustainability of the UK automotive supply chain considering simultaneously the three dimensions of sustainability (economic, social and environmental) representing the Triple Bottom Line approach.

- Remanufacturing option is considered in the paper entitled "Understanding the benefits of product-service systems for parties involved in remanufacturing". Authors attempted to investigate how the Product service systems benefit OEMs, remanufacturers and customers.

- In "Determining Decoupling Points in a Supply Chain Networks using NSGA II Algorithm" author formulated a multi-objective model to minimize the production cost and delivery time to customer and maximize the satisfaction of customer. Non-Dominated Sorting Genetic Algorithm (NSGA-II) is used to solve the proposed problem.

- In "An integrated information system to support supply chain management \& performance in SMEs", authors tried to examine the relation between the level of supply chain management adoption and small \& medium enterprises (SMEs) performance. They conduct a survey to SMEs operating in retail sector in Indonesia. 
- F. Alshubiri examined the green logistics activities and their effects on sustainable monetary expansion indicators of Sultanate of Oman in his manuscript entitled "The Impact of Green Logistics based Activities on Sustainable Monetary Expansion Indicators of Oman”.

\section{References}

Demirel, E., Demirel, N., Gökçen, H. (2016). A mixed integer linear programming model to optimize reverse logistics activities of end-of-life vehicles in Turkey. Journal of Cleaner Production, 112(2016), 2101-2113. https://doi.org/10.1016/j.jclepro.2014.10.079

Chen, J.M., Chang C. (2012). The Co-opetitive Strategy of a Closed-loop Supply Chain with Remanufacturing. Transportation Research Part E: Logistics and Transportation Review, 48(2), 387-400. https://doi.org/10.1016/j.tre.2011.10.001

Thierry M., Salomon M., Van Nunen J., Van Waasenhove L. (1995). Strategic issues in product recovery management. California Management Review, 37(2), 114-135. https://doi.org/10.2307/41165792

Journal of Industrial Engineering and Management, 2017 (www.jiem.org)

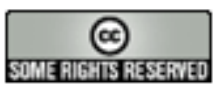

Article's contents are provided on an Attribution-Non Commercial 3.0 Creative commons license. Readers are allowed to copy, distribute and communicate article's contents, provided the author's and Journal of Industrial Engineering and Management's names are included. It must not be used for commercial purposes. To see the complete license contents, please visit http://creativecommons.org/licenses/by-nc/3.0/. 